\title{
Empirical Study on Relationship Between RMB Exchange Rate and House Price After RMB Joins SDR (Special Drawing Rights)
}

\author{
Aping Zhao ${ }^{1, *}$ Lin $\mathrm{Chen}^{2}$ \\ ${ }^{1}$ School of Economics and Management, Institute of Technology, Nanchang JiaoTong Institute, Nanchang, Jiangxi \\ 330010, China \\ ${ }^{2}$ Institute of Technology, Nanchang JiaoTong Institute, Nanchang, Jiangxi 330010, China \\ *Corresponding author. Email: 63966673@qq.com
}

\begin{abstract}
Real effective exchange rate of RMB released by Bank for International Settlements and monthly data on housing prices issued by National Bureau of Statistics were analyzed using Eviews software in the paper. Stationary test is conducted. With this as basis, the VAR (Value at Risk) model is created and the Granger causality of the model is elaborated. Results show that the real estate price serves as the Granger causation of RMB exchange rate.
\end{abstract}

Keywords: real effective exchange rate of $R M B$, real estate price index, VAR (Value at Risk) model

\section{INTRODUCTION}

Since China's housing system reform in July 1998 and exchange rate reform in August 11, 2005, research on the fluctuation of real estate price and exchange rate has been the focus of academia, and many scholars have proposed policy suggestions beneficial to economic operation. The entry of RMB into SDR in October 1, 2016 marks a milestone of its internationalization, which indicates that RMB will be employed more frequently in the fields of international finance, trade and consumption and serve as an international currency same as US dollar and British pound. The changes in international financial environment prompt the academic community to rethink the relationship between RMB exchange rate and real estate price. The real estate price index from October 2016 to December 2019 from National Bureau of Statistics and real effective exchange rate of RMB of Bank for International Settlements were adopted for empirical analysis, lending credence to conclusion.

*Funds: This paper is a phased achievement of the humanitie and social science research project of universities in Jiangxi Province: Research on the impact of exchange rate changes on real estate after RMB joins the SDR. (Project No.: JJ18227). This paper is the phased achievement of the humanistic and Social Science research project in Colleges and universities of Jiangxi Province: Study on the Reconstruction of Discourse Power of College Ideological and Political Education in the New Media Environment. (Project No.: SZZX1851)

\section{SELECTION OF MODELS, VARIABLES, AND} DATA

\section{A. Selection of models}

Some scholars inside and outside Chinese mostly employ the panel data of several countries for horizontal static comparison when studying the relationship between exchange rate and real estate price. However, this paper mainly studies the correlation between RMB exchange rate and real estate price, time series analysis method better reflecting China's policies, finance and other factors are taken, and objective conclusion are obtained. Based on dataoriented time series analysis method, VAR model that can vertically consider the dynamic influence of previous observed values of variables on variables themselves and other variables is adopted to conduct ADF test and Johansen test, in a bid to prevent spurious regression. The VAR model is also capable of elaborating the Granger causality among variables, so as to make clear the actual economic meaning of the changing relationship between RMB exchange rate and real estate price.

\section{B. Selection of variables, and data pre-processing}

Given housing system reform, exchange rate reform and the availability of data, monthly data from October 2016 to December 2019 are employed as sample interval for analysis. The following shows the selection of specific indicators for each variable. 
1) Real estate price data: House prices vary across China, and exchange rates are macroeconomic data. Accordingly, the house price of individual or partial city shouldn't be taken as sample. The real estate data pooled by National Bureau of Statistics mainly include the sales area and sales volume of commercial residential building, commodity housing, office buildings and commercial business buildings. While most people care about commodity housing. Taking all factors into consideration, the author adopts monthly housing price data obtained by commodity housing sales divided by commodity housing sales area. The data in October 2016 were processed periodically to obtain the corresponding monthly housing price index, which was recorded as HPI. Due to the absence of monthly housing price data of National Bureau of Statistics in January of each year, regression interpolation fitting of the missing part are needed to guarantee data continuity.

2) $R M B$ exchange rate data: In view of the fact that RMB officially joined SDR in October 2016 and the exchange rate of RMB against USD is too single, real effective exchange rate of RMB after October 2016 is adopted. The real effective exchange rate of RMB can avoid the one-sided factor of exchange rate against one single currency, and can reflect exchange rate of RMB comprehensively by weighting the currencies of trading partners and excluding the price change factor. To make the observation more convincing, real effective exchange rate of RMB for the sample size of 60 economies issued by Bank for International Settlements (BIS) was taken and marked as CNER.

\section{THE PROCESS AND RESULTS OF EMPIRICAL TEST}

\section{A. Single-integration test}

As mentioned above, to determine the stability of the two sets of observed data, namely real effective exchange rate of RMB and real estate price index, and thus effectively prevent spurious regression, the observed time series data should be tested by ADF test.

The null hypothesis of ADF test is $\mathrm{H}_{0}$ refers to $\delta=0$, which means that if the variable rejects the null hypothesis, the analytical variable has no unit root. The ADF test indicates that the observed values are stable. Moreover, only when the data of both variables are stable can the VAR model be established and the research results have practical significance. CNER's test results are shown in "Table I" below.

TABLE I. ADF TEST OF EXCHANGE RATE (CNER)

\begin{tabular}{|l|l|l|}
\hline & & t-statistic \\
\hline \multicolumn{2}{|l|}{ Augmented Dickey-Fuller test statistic } & -3.063021 \\
\hline Test critical values: & $1 \%$ level & -3.621023 \\
\hline & $5 \%$ level & -2.943427 \\
\hline & $10 \%$ level & -2.610263 \\
\hline
\end{tabular}

"Table I" shows that CNER's t value is -3.063021 , larger than the $1 \%$ level value: -3.621023 , but less than the 5\% level value: -2.943427 . Therefore, the original CNER time series data at the level of $5 \%$ effectively rejects the null hypothesis and passes the ADF test, which is relatively stable.

TABLE II. ADF TEST OF HPI

\begin{tabular}{|l|l|l|l|}
\hline & & t-statistic & Prob. $^{*}$ \\
\hline $\begin{array}{l}\text { Augmented Dickey-Fuller } \\
\text { test statistic }\end{array}$ & -0.604271 & 0.8579 \\
\hline Test critical values & $\begin{array}{l}1 \% \\
\text { level }\end{array}$ & -3.615588 & \\
\hline & $\begin{array}{l}5 \% \\
\text { level }\end{array}$ & -2.941145 & \\
\hline & $\begin{array}{l}10 \% \\
\text { level }\end{array}$ & -2.609066 & \\
\hline
\end{tabular}

Similarly, "Table II" shows that the $\mathrm{t}$ value of HPI from October 2016 to December 2019 is -0.604271 , greater than any one of the three confidence levels of $1 \%, 5 \%$ and $10 \%$, indicating that the original time series data of HPI accept the null hypothesis that $\mathrm{H}_{0}$ is $\delta=0$, and the observed value of HPI is unstable.

In view of HPI failing ADF test, HPI and CNER, two research variables, should be analyzed through further first-order difference test to effectively build VAR model. The results show that the two are firstorder integral at $1 \%$ confidence level, and the Johansen test can be performed.

\section{B. Johansen co-integration test}

The first-order difference based on research variables is a stationary series, so Johansen test is needed to determine the long-term equilibrium relationship between them. As long as there is a longterm equilibrium relationship between two variables, spurious regression can be effectively avoided so that the VAR model has its practical significance. In order to make the results more reliable, the lag order of the observed values was selected systematically. 
TABLE III. SELECTION RESULT OF LAG ORDER OF VAR MODEL

\begin{tabular}{|l|l|l|l|l|l|}
\hline Lag & LogL & LR & FPE & AIC & SC \\
\hline 0 & -192.3081 & NA & 315.5031 & 11.42989 & 11.51967 \\
\hline 1 & -124.5557 & 123.5484 & 7.425470 & 7.679750 & 7.949108 \\
\hline 2 & -116.6544 & $13.47873^{*}$ & $5.922759^{*}$ & $7.450260^{*}$ & $7.899190^{*}$ \\
\hline 3 & -112.9809 & 5.834462 & 6.083924 & 7.469463 & 8.097964 \\
\hline 4 & -109.3526 & 5.335622 & 6.305380 & 7.491332 & 8.299406 \\
\hline
\end{tabular}

As shown in "Table III", the likelihood ratio, Schwarz and Akaike information criterion indicate that the optimal lag order is 2 when establishing the VAR model. Since the lag order of Johansen co-integration test is 1 smaller than the optimal lag order of VAR model, the results of the co-integration test when the lag order of the model is 1 are shown in "Table IV":

TABLE IV. JOHANSEN CO-INTEGRATION TEST

\begin{tabular}{|l|l|l|l|l|}
\hline Hypothesized & & Trace & 0.05 & \\
\hline No. of CE(s) & Eigenvalue & Statistic & $\begin{array}{l}\text { Critical } \\
\text { Value }\end{array}$ & Prob.** \\
\hline None ${ }^{*}$ & 0.336485 & 15.81390 & 15.49471 & 0.0448 \\
\hline At most 1 & 0.017051 & 0.636340 & 3.841466 & 0.4250 \\
\hline \multicolumn{5}{|c}{ a. }
\end{tabular}

"Table IV" reveals the co-integration test of real effective exchange rate of RMB and real estate price index. Results show that the observed values of the two groups passed the co-integration test at the level of 5\%, and there was a long-term equilibrium relationship. Therefore, real effective exchange rate of RMB and real estate price index are well placed to build VAR model.

\section{VAR model estimation}

As mentioned in the selection of the previous model, VAR model is a model established by regression of the study variables and their previous observations. The general expression of its model is as follows:

$$
Y_{t}=C+\sum_{i=1}^{n} A_{i} Y_{t-1}+V_{t}
$$

$Y_{t}$ is the $K$ dimensional column vector derived from variables observed in phase $t$. $C$ refers to $K \times 1$ dimensional constant vector, $A_{i}$ is $K \times K$ coefficient matrix to be estimated, and $V_{t}$ the $K \times 1$ matrix caused by random error terms. Among them, the random error term $v_{i}$ is the white noise process, and $\mathrm{n}$ is the lag order.

After determining the data stationarity through single integration and co-integration tests, the VAR model constructed with HPI and CNER time series data is as follows:

$$
Y_{t}=C+\sum_{i=1}^{n} A_{i} Y_{i-1}+V
$$

Among them, $Y_{t}=\left[\mathrm{HPI}_{t} ; \mathrm{CNER_{t }}\right]_{\text {represents the }}$ immediate value of endogenous variable; $V=\left[\varepsilon_{1} ; \varepsilon_{2}\right]$ is the random disturbance term of the regression equation; ${ }^{A}$ and $C$ are the corresponding matrices to be estimated.

Eviews software is employed to estimate the model. According to the information criterion, the optimal lag period of the VAR model is 2, and the VAR model constructed with HPI and CNER time series data is obtained. The estimation results are shown in "Table V" below:

\begin{tabular}{|c|c|c|}
\hline & CNER & HPI \\
\hline \multirow{3}{*}{ CNER(-1) } & 1.051681 & 0.039781 \\
\hline & $(0.14983)$ & $(0.26633)$ \\
\hline & [7.01927] & {$[0.14937]$} \\
\hline \multirow{3}{*}{ CNER(-2) } & -0.415932 & 0.157706 \\
\hline & (0.14944) & $(0.26565)$ \\
\hline & {$[-2.78320]$} & {$[0.59366]$} \\
\hline \multirow{3}{*}{ HPI(-1) } & 0.219817 & 0.862544 \\
\hline & $(0.09797)$ & $(0.17415)$ \\
\hline & [2.24369] & [4.95285] \\
\hline \multirow{3}{*}{ HPI(-2) } & -0.222596 & 0.110672 \\
\hline & $(0.09811)$ & $(0.17441)$ \\
\hline & {$[-2.26874]$} & {$[0.63457]$} \\
\hline \multirow{3}{*}{$\mathrm{C}$} & 44.54700 & -20.21272 \\
\hline & (12.6287) & $(22.4485)$ \\
\hline & [3.52744] & {$[-0.90040]$} \\
\hline R-squared & 0.709267 & 0.962691 \\
\hline Adj. R-squared & 0.672926 & 0.958027 \\
\hline Sum sq. resids & 39.10345 & 123.5585 \\
\hline S.E. equation & 1.105433 & 1.964994 \\
\hline F-statistic & 19.51669 & 206.4247 \\
\hline Log likelihood & -53.52364 & -74.80796 \\
\hline Akaike AIC & 3.163440 & 4.313944 \\
\hline Schwarz SC & 3.381132 & 4.531636 \\
\hline Mean dependent & 121.8959 & 114.0854 \\
\hline S.D. dependent & 1.932900 & 9.591299 \\
\hline $\begin{array}{ll}\text { Determinant resid } \\
\text { covariance (dof adj.) }\end{array}$ & 4.465535 & \\
\hline $\begin{array}{ll}\text { Determinant } & \text { resid } \\
\text { covariance }\end{array}$ & 3.340181 & \\
\hline Log likelihood & -127.3129 & \\
\hline $\begin{array}{l}\text { Akaike } \\
\text { criterion }\end{array}$ & 7.422320 & \\
\hline Schwarz criterion & 7.857703 & \\
\hline
\end{tabular}

TABLE V. ESTIMATION RESULTS OF VAR MODEL 
The estimation results of VAR model are divided into three parts. The first part shows that $\operatorname{CNER}(-1)$, CNER(-2), HPI(-1) and HPI(-2) basically pass the Ttest when the exchange rate is taken as dependent variable, and the corresponding standard error is relatively small. When the housing price is taken as dependent variable, only HPI (-1) passes the T-test, while others fail.

The second part is the significance level of the two vectors through the regression equation. The results show that the goodness of fit is excellent when the house price serves as dependent variable, $\mathrm{R}^{2}$ and the adjusted $\mathrm{R}^{2}$ are both relatively large. However, the goodness of fit is less favorable with exchange rate being dependent variable.

The third part is the eigenvalue of the residual covariance. The results indicate that the value measured by Akaike information criterion and Schwarz is relatively small and the lag time is appropriate.

1) Stability test of VAR model: The stability test of VAR model aims to pulse response analysis and variance decomposition of research variables, so as to find out the shock effect and structural impact among variables. The stability of VAR model requires that the characteristic root of CNER and HPI is less than 1. The number of characteristic roots of variables is determined by the number of variables in the model and the lag order. There are altogether 4 characteristic roots

Response of HPI to CNER

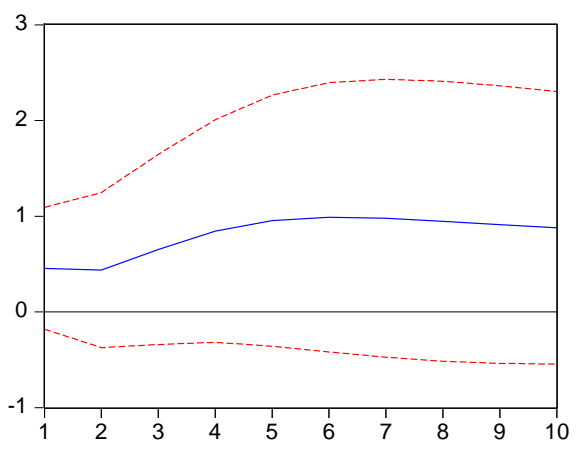

in this study, and the stability test results of the model are as follows:

TABLE VI. STABILITY TEST OF VAR MODEL

\begin{tabular}{|l|l|}
\hline Root & Modulus \\
\hline 0.971041 & 0.971041 \\
\hline $0.489069-0.287691 \mathrm{i}$ & 0.567411 \\
\hline $0.489069+0.287691 \mathrm{i}$ & 0.567411 \\
\hline-0.034953 & 0.034953 \\
\hline \multicolumn{2}{|c|}{ a. } \\
\multicolumn{1}{|c|}{ No root lies outside the unit circle } \\
b. VAR satisfies the stability condition.
\end{tabular}

The stability test results of the VAR model showed that the maximum value of the four characteristic roots of CNER and HPI was 0.971041, less than 1, which indicates that VAR model constructed by variables is stable, and it is of practical significance to carry out pulse response and variance decomposition on this basis.

2) Pulse response analysis: To describe the role of unit fluctuations with real effective exchange rate of RMB and house price index being endogenous variables respectively to explained variable subject to fluctuation, such as positive and negative changes, adjustment delay and stability process, CNER and HPI are taken as impulses and responses in this paper to analyze pulse response generated, and the results are shown in "Fig. 1":

Response of CNER to HPI

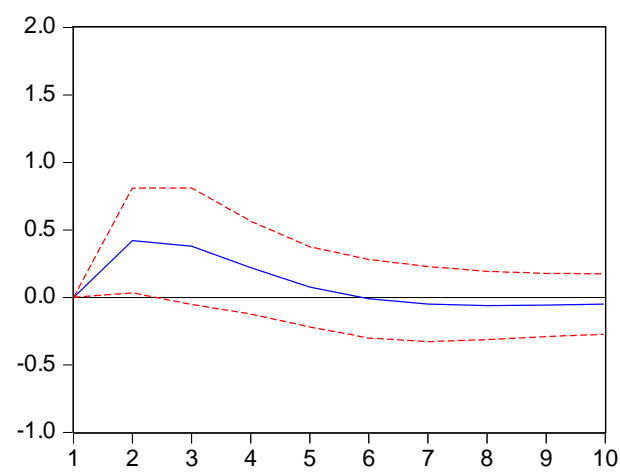

Fig. 1. Pulse response analysis. (Response to Cholesky One S.D. Innovations \pm 2 S.E.)

"Fig. 1" shows the dynamic between the two variables: CNER and HPI. Through the impulse response analysis, the following conclusions are obtained. A change of 0.5 unit in real effective exchange rate of RMB has a positive impact on the real estate price index, which is relatively small in the second phase, but has a greater impact on the subsequent phases and can last for 10 or even later periods. A 0.5 unit change in the real estate price index also has a significant impact on real effective exchange rate of $\mathrm{RMB}$, which can last to about six phase.

3) Variance decomposition: After the VAR model stability test, the variances of real effective exchange rate of $\mathrm{RMB}$ and real estate price index were decomposed into the random disturbance terms of each side. The variance decomposition of these two variables helps to determine the importance of different variable shocks in the model, which can make clear and 
compare the influence of disturbance term of real effective exchange rate of RMB and real estate price index on their respective variables in the VAR model. Percent HPI variance due to CNER

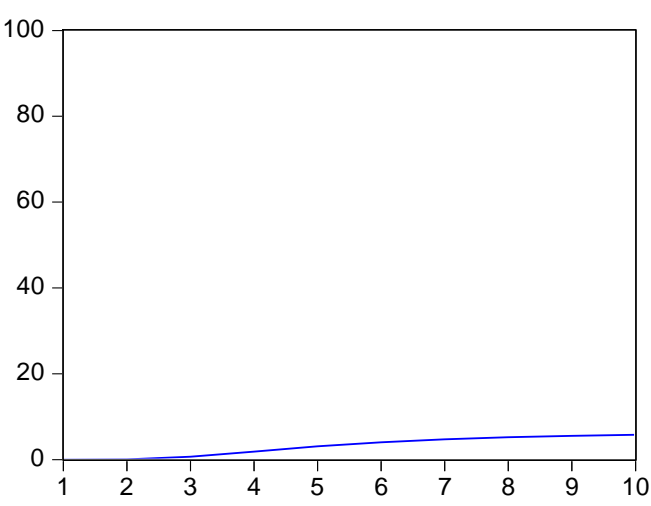

Fig. 2. Variance decomposition.

"Fig. 2" shows that the variable shock of CNER hugely sway its fluctuation, reaching about $93 \%$ in the 10th phase, while that on HPI is relatively small, only about $7 \%$ in the 10th phase. The impact of real estate price index on real effective exchange rate of RMB is gradually increasing, reaching about $20 \%$ in the third phase, while the impact on its own fluctuation is also gradually decreasing, basically stabilizing at around $80 \%$ after the third phase. This indicates that the impact of real estate price index in VAR model is more important.

\section{Granger causality test}

In order to determine the Granger causality between CNER and HPI, the two variables should be explanatory variables and explained variables respectively. The logic behind is as follows. When real effective exchange rate of RMB serves as explanatory variables, attention should be paid to whether it causes the change of the real estate price index. That is, to what extent can the real estate price index, as an explained variable, be explained by the previous real effective exchange rate of $\mathrm{RMB}$, and whether the degree of explanation will be improved after adding the lag value of real effective exchange rate of RMB. If the real effective exchange rate of RMB is improved in the prediction of real estate price index, or the correlation coefficient with real estate price index is statistically significant, it can be said that real effective exchange rate of RMB is the Granger reason of real estate price index. Similarly, when real estate price index is the explanatory variable and real effective exchange rate of RMB is the explained variable, whether the real estate price index is the Granger reason for real effective exchange rate of RMB can be obtained.
In order to make variance decomposition of variables more visible, the results are shown in "Fig. 2" below:

Percent CNER variance due to HPI

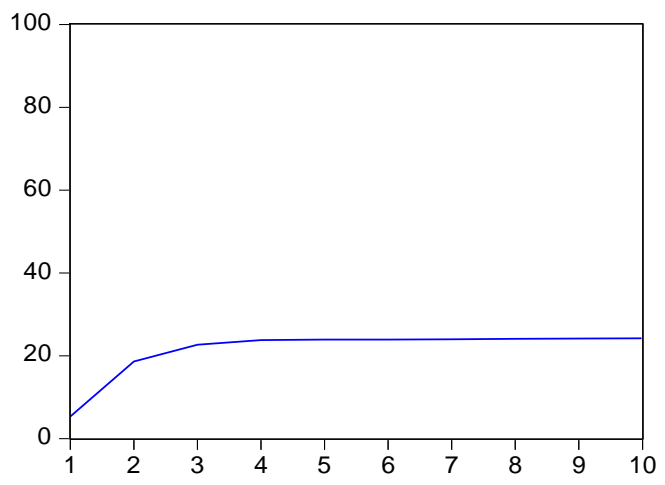

According to the principle of Granger causality, the raw time series data of real effective exchange rate of RMB and real estate price index from October 2016 to December 2019 are processed through Eviews, and the results are shown in "Table VII":

TABLE VII. GRANGER CAUSALITY TEST

\begin{tabular}{|l|l|l|l|}
\hline \multicolumn{4}{|l|}{ Dependent variable: CNER } \\
\hline Excluded & Chi-sq & df & Prob. \\
\hline HPI & 5.156375 & 2 & 0.0759 \\
\hline All & 5.156375 & 2 & 0.0759 \\
\hline Dependent variable: HPI & Chi-sq & df & Prob. \\
\hline Excluded & 1.215451 & 2 & 0.5446 \\
\hline CNER & 1.215451 & 2 & 0.5446 \\
\hline All & & &
\end{tabular}

$\chi^{2}(p)$ can be adopted to determine Granger causation. "Table VII" shows that if the dependent variable is CNER and the independent variable is HPI, $\chi^{2}$ statistic is 5.156375 at the significance level of less than $10 \%$ and close to $5 \%$, and the overall joint distribution of $\chi^{2}$ is also close to $5 \%$, it can be considered that the null hypothesis is rejected, and the housing price index will affect the real effective exchange rate of RMB. On the other hand, if HPI is the dependent variable and CNER is the independent variable, $\chi^{2}$ test is relatively small, which is 1.215451 , and the probability is $54.46 \%$, significantly greater than $5 \%$, then the null hypothesis cannot be rejected. Therefore, the change of housing price index caused by real effective exchange rate of RMB caused by CNER cannot be sure. 


\section{CONCLUSION}

In this paper, VAR model is established on the basis of determining the long-term stable relationship between real estate price index and real effective exchange rate of $\mathrm{RMB}$, so as to effectively avoid spurious regression and make the model analysis practical. After the stability of VAR model is determined, the Impulse Response analysis, Variance Decomposition analysis and Granger causality analysis among variables are conducted and the following conclusions are drawn.

First, results of pulse response analysis show that exchange rate and real estate price are related due to the accession of RMB into SDR, and further openness of capital market, and the two complement each other. The specific action process is as follows: the rise (fall) of real estate price index leads to the rise (fall) of real effective exchange rate of RMB, which in turn leads to the rise (fall) of real estate price index. The fluctuation of real effective exchange rate of RMB positively sway real estate price index and lasts for a long time, while real estate price index changes significantly affect real effective exchange rate of RMB in the initial stage, but the duration is short. After the accession of RMB to $\mathrm{SDR}$, the new financial dynamic requires further open capital market for the internationalization of RMB, which inevitably leads to the increase of capital inflow and further changes the RMB exchange rate and real estate price. Despite the lucrative return through investment in real estate market thanks to the appreciation of both real estate and RMB, investment in foreign exchange market won favor too, given its acceptance of short-term investment and certain or even no limitation compared with real estate market. Such dilemma will further change the relation of real estate price and exchange rate.

Second, the variance decomposition results show that the impact of HPI on the model is huge. This can be mostly explained by increasingly weakened dual nature of real estate after China's constant adjustment of prices, especially the investment nature. Measures including curbs on home purchases and sales taxes have effectively restrained property price hiking, forcing profit-seeking capital to shift to other markets, such as the foreign exchange market, which will drive exchange rate volatility. At the same time, RMB joined SDR after October 2016. The further opening of the capital market is in sharp contrast to the real estate market, which further increases the influence of exchange rate fluctuations on real estate price.

Thirdly, the change of HPI will incur the change of CNER in the same direction, that is, HPI is the one-way Granger cause of CNER, which coincides with the research results of some scholars before. Measures such as purchase restriction lead to a large amount of capital invested in real estate turning to the foreign exchange market, which will inevitably lead to great fluctuations in the exchange rate. But there is no minimum investment in foreign exchange market. Therefore, the fluctuation of real estate price can incur the fluctuation of exchange rate, but the latter has little such power on the former.

\section{References}

[1] Han Xintao, Liu Xing. Can the Changes in Exchange Rates have Spillover Effects on the Real Estate Price's Fluctuations? Evidence from China's Real Estate Market 1997-2015 [J]. Chinese Journal of Management Science. 2017 (04). (in Chinese)

[2] Xiao Xiao, Zhang Jing, Liu Xiaohui. Classified Capital Flow and Exchange-rate Regime - Evidence from 162 Economies [J]. Studies of International Finance. 2017 (04). (in Chinese)

[3] Will the euro increase foreign direct investment in the real estate industry? Evidence from the German case [J]. Choi Changgyu, Gyeongsang Park. European Journal of Real Estate Research. 2012 (1)

[4] Mexico's capital flow and real exchange rate appreciation [J] Carlos Ibarra (Carlos A. World Development. 2011 (12)

[5] Mckinnon, Ronald\&Gunther Schnabel. China and Its Dollar Exchanger Rate: A Worldwide Stabilizing Influence [R]. CESifo Working Paper, 2011.

[6] Ohno, Sanae\&Junko Shimizu. Do the Exchange Rate Arrangement and Capital Control Influence International Capital Flow and Housing Price in Asia [J]. Economic Inquiry, 2012(46):214-216. 